Archived version from NCDOCKS Institutional Repository http://libres.uncg.edu/ir/asu/

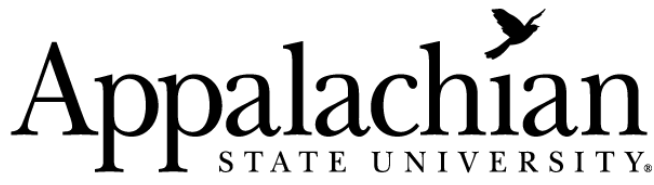

B O O NE, NORTH CAROLINA

\section{The Effects Of Air Quality Regulations On The Location Decisions Of Pollution-Intensive Manufacturing Plants}

\author{
By: Simon Condliffe and O. Ashton Morgan
}

\begin{abstract}
This research examines the effects of the 1977 Clean Air Act Amendments (CAAA) on the location decisions of pollution-intensive manufacturing plants. We develop a panel data set to analyze plant births of polluting manufacturers over time as a function county-level attainment status of the federal standard for ozone pollution. We find that more stringent county-level environmental regulations impact pollution-intensive capital flows through deterring new plant births. We also find that the impact of stricter regulations varies by pollution-intensity of manufacturers, with results suggesting that federal guidelines have a greater impact on high pollution intensive manufacturers than more moderate polluters.
\end{abstract}

Condliffe, S. and Morgan, O.A. (2009) "The Effects Of Air Quality Regulation Enforcement And The Firm Location Decision Among U.S. Counties." Journal of Regulatory Economics, 36(1): 83-93, 2009 (Aug 2009). Version of Record Available At www.Springer.com (ISSN: 0922-680X). [DOI 10.1007/s11149-008-9064-1] 


\section{INTRODUCTION}

The relationship between the spatial heterogeneity in environmental regulations and the firm location decision for polluting manufacturers has been debated in the academic and legislative arena for a number of years. Central to the debate is the argument that interjurisdictional competition will induce a "race to the bottom" phenomenon where local legislators set environmental regulatory standards below optimal levels to attract polluting industries to the region.

The general theoretical assumption is that lax environmental regulatory standards attract capital flows (Kahn 1997; List and Mason 2001), yet support from the empirical literature is divided. In general, earlier studies find little or no statistical evidence of a relationship between environmental regulation and firm location. More recent empirical work largely contradicts earlier research, citing a number of shortcomings in earlier data sets and estimation techniques and, in general, provides much stronger statistical support for the hypothesis that the firm location decision is affected by more stringent regulatory standards.

An example of earlier research, Bartik (1988) uses a conditional logit model to measure the impact of a number of regulatory measures on new manufacturing plants opened by the Fortune 500 companies between 1972 and 1978 . He finds no significant relationship in any of the regulatory coefficients. McConnell and Schwab (1990) examine the location decision of motor vehicle assembly plants between the years 1973 and 1982 and find no impact of regulatory enforcement or manufacturing abatement expenditures on the firms' location decisions. Duffo-Deno (1992) examines the relationship between manufacturing abatement costs and Standard Metropolitan Statistical Area (SMSA) earnings and employment growth, and while he finds a negative relationship, the impact is slight. Levinson (1996) considers six environmental indicators but finds that the effects of more stringent regulations on firm location are small and do not vary as expected with the pollution intensity of the industry.

In line with recent research supporting the hypothesis of environmental regulations impacting firm location, List et al. (1999) focus on air quality attainment standards. Although they find that plant location decisions are largely uncorrelated with county attainment levels, for pollution-intensive firms, they find statistical evidence of a decrease in the number of births in counties that failed to meet federal air quality standards. Becker and Henderson (2000) use a conditional Poissonmodel and find that air quality regulations significantly reduce the number of births in nonattainment areas relative to attainment areas. Further, List (2001) considers new foreign manufacturing births in counties throughout California between 1983 and 1992, and finds that more stringent pollution regulations have a negative effect on new manufacturing plants in pollution-intensive industries. Henderson (1996), Keller and Levinson (1999), List and McHone (2000), and List et al. (2004) all add further support to the hypothesis of regulatory impacts.

In acknowledging the disparity in empirical findings, a number of common shortcomings are apparent in earlier work. First, data limitations narrowed the scope of studies in terms of industrial or geographical detail. Due to the unavailability of micro data on establishments, economists had to settle with aggregate measures of economic activity as proxies for establishment locational choices. This simplifies the estimation but at the expense of aggregation bias. For example, as regulations based on a county's 
attainment status are more stringent toward new plants, then plant births may be more sensitive to environmental regulations than existing plants in the same industry. As such, use of aggregate data on the stock of plants will not pick up regulatory effects on the flow of plant births. Some more recent research (List and McHone 2000) avoids this problem by examining plant births at the county level; however, while avoiding the potential for aggregation bias, this often comes at the expense of examining smaller geographic areas, such as individual states.1 In turn, Jeppesen et al. (2002) argue that the smaller the geographic area of the study, the larger the estimated influence of environmental regulation on new plant location decisions.

A second general shortcoming of earlier research concerns aggregating births across year intervals. Primarily due to data limitations, some research (Levinson 1996; Becker and Henderson 2000; List 2001) use estimates for the number of plant births across 5-year intervals. For example, Levinson (1996) uses Census data to estimate the number of new plant births between 1982 and 1987 assuming that manufacturing establishments in the 1987 Census that were not in the 1982 Census are by definition, new plants. While measuring plant births as the dependent variable, the temporal aggregation has potential problems in missing new plants that open and shut down within the 5-year window.

Finally, many earlier studies use cross-sectional models that fail to control for the simultaneous nature of firm location and pollution problems. List and McHone (2000) argue that this will lead to biased coefficient estimates as higher pollution levels, firm location, and more stringent regulatory controls are positively correlated cross-sectionally. They also suggest that analyzing the difference between new firm births in a region over a specified time period as a function of the difference in the region's environmental regulation over the same time period is much more informative than considering the inter-regional variation of the same variables at one point in time. We follow the model used by Becker and Henderson (2000) by developing a panel data set to examine whether environmental regulatory stringency impacts the location decision of new pollution-intensive plant births. Our measure of environmental regulation is the attainment status of the federal standard for ozone pollution. $2 \mathrm{We}$ also disaggregate the data into low-, medium-, and high-polluting manufacturing industries allowing us to test whether the impact of environmental regulation varies across the pollution intensity of plants. List and McHone (2000) argue that while effects of environmental regulation may be minimal at the aggregate level, some industries, such as heavy polluters, may be more significantly affected by environmental regulation standards than others.

The paper addresses a number of the shortcomings in the existing literature on locational behavior and the incidence of polluting manufacturing firms by using a newly available data set of establishment births and deaths, across all counties in the contiguous United States, representing a greater level of data than is typically used in other firm location studies. Specifically, by considering all new plant births in pollutionintensive manufacturing industries across all counties in the contiguous US, we avoid data constraints and estimation bias in previous studies.

Estimation results from a Poisson panel data model reveal that the location decisions for pollution-intensive manufacturing plants are negatively impacted by our regulatory stringency measure. This result supports the recent work by Henderson (1996), Becker and Henderson (2000), List and McHone (2000), and List et al. (2004) and provides 
important empirical evidence toward the future development of pollution control strategies. Also, disaggregation by pollution intensity indicates that the location decisions of The most pollution-intensive new manufacturing plants are more significantly impacted than more moderate polluters.

The remainder of the paper is organized as follows. The next section provides a brief overview on the history of air quality regulations in the US. Then, the data are discussed before presenting the empirical model. Finally, results and concluding remarks are presented and discussed.

\section{AIR QUALITY REGULATION}

Prior to the 1970s, responsibility for regulating air polluting establishments fell primarily under the auspices of state governments. Since this time, the federal government has taken more responsibility for environmental regulation control beginning with Congress passing theNational Environmental PolicyAct and amendments to the Clean Air Act, as well as creating administrative bodies such as the Environmental Protection Agency (EPA) and the Council on Environmental Quality to enforce new regulatory statutes. The EPA established national ambient air quality standards (NAAQS) that set standards on different polluting criteria to all regions throughout the US. However, this created problems for individual states as they were required to submit a state implementation plan (SIP) to detail how they would bring nonattainment areas into attainment. Not all states had the necessary resources to comply with stricter environmental regulations and that created uncertainty regarding how attainment could be achieved. Coupled with other problems, the federal government passed the 1977 Clean Air Amendments Act (CAAA).

Under the 1977 amendment, each July, every county in the US is classified as either in-attainment or out-of-attainment with regard to the national standards for each of the five criteria air pollutants. If a county is out-of-attainment, the state is required to submit a SIP indicating its plans to bring out-of-attainment areas into attainment of NAAQS.

New plants locating in out-of-attainment areas face much stricter regulatory measures relative to those locating in attainment areas. For example, new polluting plants located in out-of-attainment areas are subject under federal guidelines to the lowest achievable emission rate (LAER) without consideration of cost. As such, plants must install the cleanest available technology. These abatement expenditures can represent significant installation costs for pollution-intensive plants. New polluting plants may also be required to purchase pollution offsets from existing plants. In contrast, only new plants locating in in-attainment areas that are Class A3 polluters are subject to these regulations. Even then, new plants are only required to install the best available control technology (BACT), which represents a weaker standard than LAER, and so, new polluting plants face much less costly regulation. Also, new plants that do not represent Class A polluters are not subject to regulation. In terms of equipment for existing plants within nonattainment areas, equipment is subject to reasonably available control technology whereas equipment for existing firms in in-attainment areas is not subject to regulatory control. 


\section{DATA}

The primary data are drawn from a custom data set of establishment births and deaths from the Department of Statistics of US. Business, a branch of the Census Bureau.4 Observations in the data set are the number of county level establishment births by three-digit SIC industries. The data set is a complete census of establishment births and deaths in the US. Unlike other sources, such as County Business Patterns, employment data, or Dun and Bradstreet's business starts data, there is no suppression of data for disclosure reasons. The Census Bureau matches establishments across years and verifies each recorded birth and death to ensure that the establishment has not merely been renamed, merged with another establishment, or been otherwise reclassified (all of which are sources of mismeasurement in other data sets). A description of variables used in estimation is provided in Table 1.

Table 1 Definition of variables

\begin{tabular}{|c|c|c|c|}
\hline Variable & Definition and source & Mean & Standard dev. \\
\hline All births & $\begin{array}{l}\text { Number of county level establishment births in } \\
\text { polluting industries by three-digit SIC indus- } \\
\text { tries. Department of Statistics of US business }\end{array}$ & 3.219 & 21.498 \\
\hline High-polluters & $\begin{array}{l}\text { Number of county level establishment births } \\
\text { in high-polluting industries by three-digit SIC } \\
\text { industries }\end{array}$ & 0.248 & 0.904 \\
\hline Medium-polluters & $\begin{array}{l}\text { Number of county level establishment births in } \\
\text { medium-polluting industries by three-digit SIC } \\
\text { industries }\end{array}$ & 0.992 & 4.775 \\
\hline Low-polluters & $\begin{array}{l}\text { Number of county level establishment births } \\
\text { in low-polluting industries by three-digit SIC } \\
\text { industries }\end{array}$ & 2.019 & 17.569 \\
\hline Attainment status & $\begin{array}{l}\text { County-level regulatory standard. Dummy vari- } \\
\text { able }=1 \text { if county out-of-attainment if federal } \\
\text { standard for ozone, } 0 \text { otherwise. Federal regis- } \\
\text { ter title } 40 \text { CFR Part } 81.305\end{array}$ & 0.090 & 0.286 \\
\hline Income per capita & Per capita personal income by county, BEA & 19,833 & 4,462 \\
\hline Population & Population by county, BEA & 86,615 & 282,052 \\
\hline Property tax per capita & Property tax revenue per capita, Census Bureau & 200.0 & 267.0 \\
\hline
\end{tabular}


Table 2 Manufacturing industries by polluting intensity

Source: Gamper-Rabindran (2006)

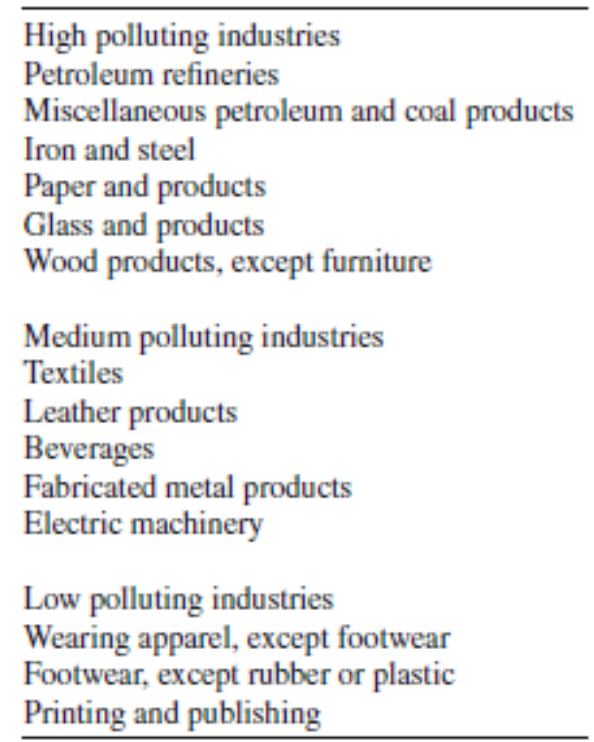

Petroleum refineries

Miscellaneous petroleum and coal products

Iron and steel

Paper and products

Glass and products

Medium polluting industries

Textiles

Leather products

Beverages

Low polluting industries

Wearing apparel, except footwear

Printing and publishing

All data on firm births are for the inter-year periods 1996-1997 and 1997-1998. In order to test the locational behavior response of manufacturers of varying polluting levels, we identify polluting manufacturers using the Gamper-Rabindran (2006) classification scheme. A breakdown of pollution-intensive industries by intensity is provided in Table 2.

Data on county-level ozone attainment status was collected from the US. Environmental Protection Agency Green Book. Attainment status information is provided for each US county from 1992 to present, detailing reclassification from in-attainment to out-of-attainment for the primary federal standard for ozone by year. Finally, the Bureau of Economic Analysis provides personal income per capita and population data by county, and the Census Bureau provides property tax data by county.

\section{EMPIRICAL MODEL}

To derive the reduced-form empirical model, we follow Becker and Henderson (2000) and adapt the stock model in Henderson et al. (1995) to a flow concept. This allows us to capture the effect of increased pollution regulatory measures in a partial equilibrium framework. In each separate industry, we assume that in any given time period, there is a supply of entrepreneurs in each county that might enter the industry given by

$$
Y_{i t}\left(\prod\left(X_{i t}, e_{i t}\right)\right)
$$


where $Y_{i t}$ is the flow of newplants (gross births), $X_{i t}$ are spatial attributes that affect the local profit function, $\Pi$, and $e_{i t}$ is a random error component. The supply relationship to a county between births and profit per plant space is upward sloping, indicating that the higher the per firm profit, more firms will be enticed into the industry. The curve may shift as county size changes, therefore, the $X_{i t}$ are shift parameters influencing the location of the curve.

To represent profit opportunities for new firms, there is also a corresponding demand curve that depicts changes in per firm profit as a result of an increase in births. The demand curve can be locally upward sloping as births can positively affect per firm profits through localization or urbanization economies, or downward sloping as a negative impact on local output price can reduce per firm profit.

Total births are given by the intersection of the demand and supply curves, in birth per firm profit space. This gives us a reduced-form equation

$$
Y_{i t}=f\left(X_{i t}\right)+e_{i t}
$$

where $Y i t$ represents births in county $i$ in time $t ; X_{i t}$ is a vector of county attributes presumed to influence the spatial location function; and $e_{i t}$ is a contemporaneous independently and identically distributed error term.

As the number of births are strictly integer values that are generally close to zero, $Y_{i t}$ is modeled as a Poisson distributed random variable. The Poisson distribution is appropriate due to the preponderance of zeros and the discrete nature of the dependent variable. Equation 1 is estimated using the conditional Poisson model in Hausman et al. (1984), with robust standard errors (Wooldridge 1991). The property of the Poisson distribution indicates that the mean of $Y_{i t}$ is equivalent to the variance of $Y_{i t}$. In the basic Poisson model, the probability of observing $Y_{i t}$ births in county $i$ at time $t$ is

$$
\operatorname{prob}\left(Y_{i t}\right)=\frac{e^{-\lambda_{i t}} \lambda_{i t}^{y_{i t}}}{Y_{i t} !}, \quad y=0,1,2, \ldots
$$

where $\lambda_{i t}$ is the Poisson parameter or the expected value of $X_{i t}$. The Poisson parameter is given by

$$
\lambda_{i t}=e^{x_{i t} \beta+\alpha_{i}},
$$

(4)

where In $\lambda_{i t}=\beta^{\prime} X_{i t}+\alpha_{i} ; \beta$ is a vector of unknown parameters to be estimated; and $\alpha i$ are unobservable county-specific factors that may affect the location decision. Taking the natural approach of accounting for heterogeneity in the standard linear panel data model by transforming the variables about their means does not remove heterogeneity in the Poisson framework. Instead, in estimation, the fixed effect is 
conditioned out by modeling the event in the likelihood function as the sequence of births in a county over time, conditional on total births for that county over the sample period. Hence, the likelihood function becomes

$$
\operatorname{prob}\left(Y_{i 1}, Y_{i 2}, \ldots Y_{i T} \mid \sum_{t} Y_{i t}\right)=\frac{\left(\sum_{t} Y_{i t}\right) !}{\prod_{t}\left(Y_{i t} !\right)} \prod_{t}\left[\frac{e^{x_{i t} \beta}}{\sum_{t} e^{x_{i t} \beta}}\right]^{Y_{i t}}
$$

The conditional Poisson model captures between-county variation by the county fixed effects, leaving only within-county variation to be explained. An alternative modeling procedure (Levinson 1996; Gray 1997; List et al. 1999) is the conditional logit framework. If one reasons that unobserved characteristics of counties (such as labor productivity) are important in a firm's location decision, and such factors should be controlled, a within-county approach such as ours is appropriate. However, a cross-sectional logit model may be appropriate if one attempts to model the attractiveness of a county relative to others. The conditional Poisson model avoids some of the weaknesses of a cross-section logit model, such as omitted variable bias.

\section{RESULTS}

Estimation results from the conditional Poisson models are presented in Tables 3 and 4. The high $R 2$ measure of goodness of fit suggests that the Poisson model is appropriate. In total, we ran four versions of the model. The full model is presented in Table 3 and uses establishment births for all polluting industries as the dependent variable. The other threemodels disaggregate the dependent variable by pollution intensity to examine the impact of the explanatory variables on new establishments of low-, medium-, and high-polluting industries. Disaggregated results are presented in Table 4.

We also consider the potential for endogeneity of the attainment status variable. An endogeneity issue may exist as new firm births in a specific county could increase pollution levels for the county as a whole, potentially causing the county tomove from an in-attainment to out-of-attainment status. We follow List and McHone (2000) and empirically check for endogeneity by running a second set of models using lagged values of attainment status and comparing results. The coefficients do not change significantly from the presented models indicating that endogeneity of the attainment status variable is not an issue in the data. 
Table 3 Conditional poisson estimates-full model

** Significant at the $5 \%$ level

\begin{tabular}{lc}
\hline Variable & \multicolumn{1}{c}{ All births } \\
\hline Population & $1.136^{* *}(0.006)$ \\
Income & $1.192^{* *}(0.031)$ \\
Attainment & $-0.095^{* *}(0.018)$ \\
Property tax & $-0.396^{* *}(0.061)$ \\
Pseudo $R^{2}$ & 0.984 \\
\hline
\end{tabular}

Table 4 Conditional poisson estimates by pollution intensity

\begin{tabular}{lccc}
\hline & High-polluters & Medium-polluters & Low-polluters \\
\hline Population & $0.875^{* *}(0.021)$ & $1.046^{* *}(0.010)$ & $1.212^{* *}(0.007)$ \\
Income & $0.446^{* *}(0.135)$ & $0.868^{* *}(0.061)$ & $1.321^{* *}(0.036)$ \\
Attainment & $-0.13^{* *}(0.065)$ & $0.036(0.031)$ & $-0.014(0.022)$ \\
Property tax & $-0.603^{* *}(0.228)$ & $-0.531^{* *}(0.110)$ & $-0.197^{* *}(0.076)$ \\
Pseudo $R^{2}$ & 0.328 & 0.936 & 0.984 \\
\hline
\end{tabular}

** Significant at the $5 \%$ level

The primary finding from the full model concerns the negative and statistically significant coefficient on the attainment variable. This suggests that as a county moves from a status of in-attainment to out-of-attainment, expected new polluting plant births fall by 0.10. These results are consistent with other recent studies (Henderson 1996; Becker and Henderson 2000; List and McHone 2000; List et al. 2004) in revealing that federal standards under the 1977 CAAA may be causing a "temporal browning" 5 across counties asmore stringent air quality regulations impact capital flows. Also, the size of attainment coefficient is less than the attainment variable reported in Becker and Henderson (2000) and List et al. (2004) and less than that reported by List and McHone (2000)-although this is expected as List and McHone (2000) modeled a smaller geographic area (New York State), and so, the estimates therein are likely to be inflated.

Other results from the full model reveal that all coefficients are statistically significant at the $5 \%$ level and have the expected signs. Polluting firm births are positively impacted by county-level population. This supports a common finding in recent studies. One explanation for the positive and significant coefficient on the population variable is that polluting firms take advantage of labor-market economies by sharing a common labor pool, and so, there are more births in more densely populated areas. As expected, the coefficient on the property tax variable is negative and significant at the 5\% level-suggesting that higher property taxes deter new plant births. 6 The location decisions of polluting plants are also positively affected by counties with higher income per capita levels. Findings for income impacts are split across recent research with both positive and negative statistically significant coefficients reported. Our result rejects environmental justice concerns that polluting manufacturers locate plants in disproportionately poor areas. 
Comparing results by pollution intensity also yields some interesting findings. Observing the attainment variable across models reveals that increased regulatory standards associated with moving into out-of-attainment status have a greater impact on deterring the births of more pollution-intensive manufacturers-a finding that contradicts earlier studies that employ cross-sectional analyses (Levinson 1996; Gray 1997). For example, as a county moves from in-attainment to out-of-attainment status, expected new plant births for high pollution-intensive manufacturers fall by 0.13 . Further, the effects of increased regulatory standards are statistically insignificant for low pollution-intensive plants. The result is intuitive as, under CAAA regulations, high pollution-intensive manufacturers can expect to incur greater regulatory costs to reduce pollution levels to the lowest achievable emission rate relative to more moderate pollution-intensive manufacturers. As such, one can expect high pollution-intensive manufacturers to pay more attention to a county's attainment status.

\section{CONCLUSION}

Under the 1977 CAAA, counties moving from in-attainment to out-of-attainment are subject under federal guidelines to the lowest achievable emission rates, requiring new plants to install the cleanest available technology. Empirical studies over the last 20 years have examined whether increased stringency in environmental regulations impact the location decision of polluting manufacturing plants. The majority of studies suggest that increased environmental regulatory stringency has no affect on location behavior, or at best, the relationship is negligible. We use newly available panel data with broad coverage of the US that provide a more generalized result than previous micro research and analyze plant births of polluting manufacturers over time as a function of county-level attainment status of the federal standard for ozone pollution. The results provide evidence that movement to out-of-attainment status significantly deters new high-polluting plant births in the affected counties. This suggests that the expected abatement expenditures under the CAAA represent significant installation costs for new pollution-intensive plants, and as such, impact firm location behavior. This finding provides an important policy note for future pollution control strategies and their implications on the spatial distribution of pollution-intensive firms as our results suggest a temporal browning process under current regulations, with polluting manufacturers more likely to locate in counties that are in-attainment of the federal standard, attracted by the lower regulatory costs imposed.

We also find that stricter environmental standards as counties move into out-of attainment status have a greater impact on deterring new births of more pollution intensive plants as manufacturers face relatively higher abatement expenditures to reduce pollution levels to lowest achievable emission rates. 


\section{NOTES}

1 For example, List andMcHone analyze plant births in New York State while List (2001) considers foreign firm births in California.

2 As the focus of the study is on plant births in pollution intensive (dirty) industries, the air quality pollutant that has received the most attention since the 1977 Clean Air Amendments Act is ozone.

3 Plants considered as class A polluters are those with the potential to emit more than 100 tons of a criterion pollutant on an annual basis.

4 The data were compiled by the Bureau of the Census specifically for this research. Hence the custom nature of the data set.

5 See List and McHone (2000).

6 Due to missing observations on property tax in some counties, we also include a dummy variable to capture the missing property tax data. We do not report the dummy coefficient in the results as a second model run without the missing property tax dummy yields the same results on all reported variables.

\section{REFERENCES}

Bartik, T. J. (1988). The effects of environmental regulation on business location in the United States. Growth and Change, (Summer), 22-44.

Becker, R., \& Henderson, J. V. (2000). Effects of air quality regulation on polluting industries. Journal of Political Economy, 108, 379-421.

Duffo-Deno, K. T. (1992). Pollution abatement expenditures and regional manufacturing activity. Journal of Regional Science, 32(4), 419-436.

Gamper-Rabindran, S. (2006). NAFTA and the environment: What can the data tell us? Economic Development and Cultural Change, 54(3), 605-633.

Gray, W. B. (1997). Manufacturing plant location: Does state pollution regulation matter? Working Paper No. W5880, National Bureau of Economic Research.

Hausman, J., Hall, B. H., \& Griliches, Z. (1984). Econometric models for count data with an application to the patents-R\&D relationship. Econometrica, 52, 909-938.

Henderson, J. V. (1996). Effects of air quality regulation. American Economic Review, 86, 789813.

Henderson, J., Vernon, K. A., \& Turner, M. (1995). Industrial development in cities. Journal of Political Economy, 103, 1067-1090.

Jeppesen, T., List, J., \& Folmer, H. (2002). Environmental regulations and new plant location decisions: Evidence from a meta-analysis. Journal of Regional Science, 42(1), 19-49. 
Kahn, M. (1997). Particulate pollution trends in the United States. Regional Science and Urban Economics, 27, 87-107.

Keller, W., \& Levinson, A. (1999). Environmental regulations and FDI inflows to U.S. states: The Potential for a 'Race to the Bottom' of environmental stringency. Paper prepared for the ISIT99 Conference, June

4-5.

Levinson, A. (1996). Environmental regulations and manufacturer's location choices: Evidence from the census of manufacturers. Journal of Public Economics, 61(1), 5-29.

List, J. (2001). U.S. County-level determinants of inbound FDI: Evidence from a two-step modified count data model. International Journal of Industrial Organization, 19, 953-973.

List, J., \& Mason, C. F. (2001). Optimal institutional arrangements for pollution control: Evidence from a differential game with asymmetric players. Journal of Environmental Economics and Management, 42(3), 277-296.

List, J., \& McHone, W. (2000). Measuring the effects of air quality regulations on "Dirty" firm births: Evidence from the Neo- and mature-regulatory periods. Papers in Regional Science, 79(2), 177-190.

List, J., McHone, W., \& Millimet, D. (2004). Effects of environmental regulation on foreign and domestic plant births: Is there home filed advantage? Journal of Urban Economics, 56(2), 303326.

List, J., McHone, W., Lee, J.,\& Soskin,M. (1999). Effects of air quality regulation on manufacturing births: Evidence from a panel of counties in New York state. Working paper, AREC, University of Maryland.

McConnell, V. D., \& Schwab, R. M. (1990). The impact of environmental regulation on industry location decisions: The motor vehicle industry. Land Economics, 66(1), 67-81.

Wooldridge, J. (1991). Specification testing and quasi-maximum likelihood estimation. Journal of Econometrics, 47, 980-995. 